\title{
Understanding Modern Learning Environment (MLE) in Big Data Era
}

\author{
https://doi.org/10.3991/ijet.v13i05.8042 \\ Miftachul Huda \\ Universiti Teknologi Malaysia, Malaysia \\ Andino Maseleno $\left({ }^{\bowtie}\right)$ \\ STMIK Pringsewu, Lampung, Indonesia \\ andimaseleno@gmail.com \\ Kamarul Shukri Mat Teh \\ Universiti Sultan Zainal Abidin, Malaysia \\ Abdul Ghafar Don \\ Universiti Kebangsaan Malaysia, Malaysia \\ Bushrah Basiron, Kamarul Azmi Jasmi, \\ Mohd Ismail Mustari, Badlihisham Mohd Nasir \\ Universiti Teknologi Malaysia, Malaysia \\ Roslee Ahmad \\ Universiti Islam Sains Malaysia, Malaysia
}

\begin{abstract}
Modern Learning Environment (MLE) to support learning in big data era, its exploration where the students are engaged to access online resources using their mobile devices, laptop and other digital devices needs to understand MLE as the term integrated between digital technology tools and learning skills. The convenient facilitation has a whole section designed to support learning styles which can exactly create the learning environment to be modern. This paper aims to explore innovative design for MLE with big data approach to see the chance in applying this model for the construction to the design of big data based learning environments to facilitate online learning towards information and knowledge in higher education setting. The finding reveals to propose model reference to be implemented to improve student learning outcomes in a technology-rich teaching and learning environment in higher education. As a result, this paper is expected to contribute in the support with an initiative in the learning performance.
\end{abstract}

Keywords-Big data, modern learning environment (MLE), higher education, flexible learning, accessible resources 


\section{Introduction}

In the effort to enhance the educational outcomes with the quality performance, integration between adaptive technology and learning skills has emerged to transform online learning as the trend and model in providing access on the resources and information [1], and collaborative learning with borderless space [2]. Encompassing pedagogical, social and technological elements as the design for implementation processes to offer some necessary benefits like flexibility, openness and access to resources in learning process [3], Modern Learning Environment (MLE) is considered in supporting strengths-based instruction to add the value on the students' learning experiences and also create new relevance and connection beyond the school boundary [4]. It can be seen from the initiative of utilizing digital devices like tablets, smart phones, and laptop as the attempts to promote the practices with appropriate approach on teaching and learning in higher education setting. This improvement is to ensure that the learning process quality can be facilitated easily with online learning to enable getting resources and information available on the Internet [5]. In particular, promoting a range of pedagogical skills continuing integration with technological tools would lead to the development of learning environment that aligns better instruction in both student and teacher. In addition, making such modern part of learning environment could provide learners with open and flexible direction to facilitate traditional pedagogies to modern tools.

However, the issue is that ability to combine and manage the depiction between formal and informal learning environment has challenges to keep in touch with the development of a robust, continuously improving the practice in higher learning teaching [6]. MLE emphasising the outside view and landscape has given such benefit on the learning process in a way that is required to pay particular attention to see the current gap which may go further on. Since there has been lack of scholarly attention to see in a comprehensive approach on MLE in the era of big data, this paper aims to propose a model for enhancing learning with innovative way by incorporating big data framework in utilizing various sources of information and knowledge in higher education setting. In this study we designed to see how modern learning environment can engage with the current trend of big data era.

\section{Theoretical Framework}

\subsection{About Modern Learning Environment (MLE)}

Modern Learning Environment (MLE) is a term that has a whole section on information supported with digital technology tool in the way that can be seen as a modern part in learning and teaching process. MLE is designed to support learning styles which can exactly make the learning environment to be modern [7]. In this view, it is evident that MLE has a distinct look especially from the way on process and facilitation. What makes them modern becomes greatly distinctive from the traditional look such as school classrooms. In particular, the extent to such convenience refers to en- 
hance knowledge inquiry rooted in pedagogical and technological approach. As a result, MLE is a kind of educational circles required in schools and also in higher learning around the world to support the learning styles, particularly collaborative communication styles [8]. With regard to supporting learning styles in knowledge inquiry, attempts to enable student to accept the learning and additionally to get access to online resource can be facilitated with such integration. This is to consider in creating such bright which may stimulate classrooms to give such description into open and flexible learning spaces.

Combined with virtual communication through the use of digital technology in facilitating the learners in exploring the information sources [5], MLE is integrated between the pedagogical approach with condition and dynamics in extending materials [9]. As an integral part of using the digital resources to facilitate the flexible learning with borderless space, incorporating the design with interactive practice in generating the innovative and inspiring configurations for learners would have a significant essence in making innovative learning environment [10]. It can be seen from utilizing social networking for instance to run the course on certain subject matters. In addition to the strengths-based learning, the MLE facilitates students to possess flexibility, agency, ubiquity, and connectedness to support the process in working in an innovative learning environment [11]. This could make the learning process in the practice with self-regulated inquiry, since the students would have chance to generate their learning performance. The initiative of students' learning and performance may provide the opportunities to make students actively present their knowledge and skills. Through the MLE with big data to help learners to capture the knowledge in developing the learning activities, creating students to discover and build largely on their own understanding of information which they enhance through conceptualizing principles and relationships. This refers to some particular additional facilitation such as breakout spaces, multi-purpose spaces and technology-rich spaces [12] as shown in Figure 1.

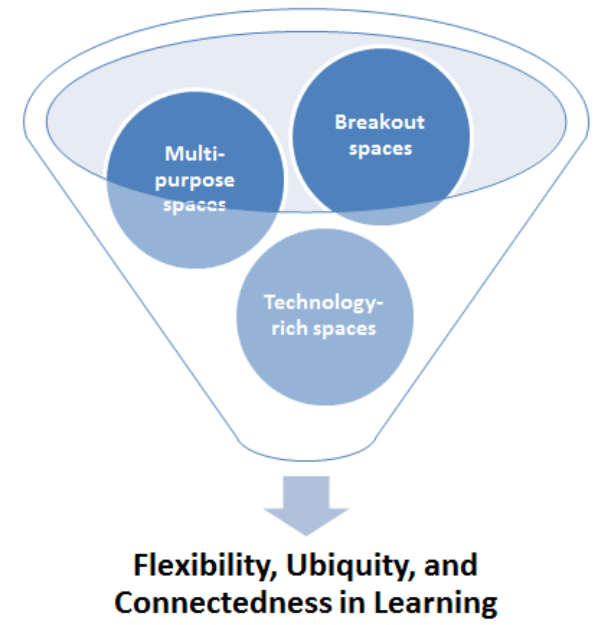

Fig. 1. Modern Learning Environment (MLE) 
As a result, the views on some elements on the modern style will help improve students' learning and outcomes which consider a great chance to enhance the learning instrument relating to the present time.

\subsection{Towards Big Data with its Valuable Insight in Education}

Known as the term to the extent in utilizing the massive amounts of data created every second across the Internet, big data is subsequently extracted to discover in analyzing design to extract large volumes of a wide variety of data to gain its potential and value for the user [13]. As the new generation designed with architectures in collecting, aggregating and analyzing massive data [14], big data with forms of advanced number of data involving velocity, volume, and variety information enables assets in processing insight discovery to customization, personalization to enhance decision making and intervention to optimize the further information process [15]. With such amount of data applied through such device with internet, transferring data information will ensure to predict the user needs, like business, learning resources, information and update news as well as product promotion advertisement [16]. Through extending the pattern accumulated from the customization, integrated transmission using enterprise software like smartphone, laptop, and any other digital tool with utilizing wireless signal can be used and extracted to access, store and transmit the convergence of data which may be conceived using the link system.

As big data is aimed at the utilization of massive amounts of data created every second across the internet, data collection can be fine-tuned to utilize specifically to innovative online learning [17]. This setting is to maximize its potential through highvelocity capture towards massive amounts of data from multiple sources to maintain the competitive advantage like multiple business scenarios, educational sector and also competitors in private sectors [14]. Big data as a key role towards the variety of contexts of data capability to discover insights about the services processes in gaining an insight to explore and understand users' behavior is used in real time to offer personalized and customized services [18]. With more important factor to consider big data in the educational context to gain its value, big data practices take place by providing new opportunities to maximize the potential of data collection in online learning systems. Moreover, also innovative teaching with the concept of big data [19] can be enhanced to optimize such opportunities from the perspective of both students and service providers [20]. Amongst government departments, universities or institutions, and policy makers, they have a great chance to offer such customization and personalization of knowledge and services. In addition, big data approach from multi channels has an extended benefit to transform the traditional learning basis to innovative basis with modern style. In learning activities, it offers emphasis on pervasive learning anywhere and anytime [21]. With such sufficient support to academic skills and social interaction to influence the effectiveness of learning, the availability of big data based technological tool becomes outstanding effort to enhance and extend existing classroom practice. Moreover, emerging shift in the forms of activities, emphasizing the use of big data needs to consider in both complemented and modified practice. To assess the educational levels of the students in providing learning ap- 
proach with such indicators of online resources, big data can be set out checking on the voluntary data on particular skills and interest designed with common core elements and themes in modern learning design.

\section{$3 \quad$ Research Methodology}

The aim of this paper attempts to propose a model for enhancing learning with innovative way by incorporating big data framework in utilizing various sources of information and knowledge in higher education setting. To see how modern learning environment can engage with the current trend of big data era, we designed this model by examining literature reviews from peer-reviewed journals, books and conference papers by using keywords modern learning environment and big data. Met-synthesis was conducted to integrate, evaluate and interpret the findings of multiple research studies. As a result, phenomenological and grounded theories and ideas extracted to identify their common features, elements, and functionalities can be integrated and used to propose a reference model.

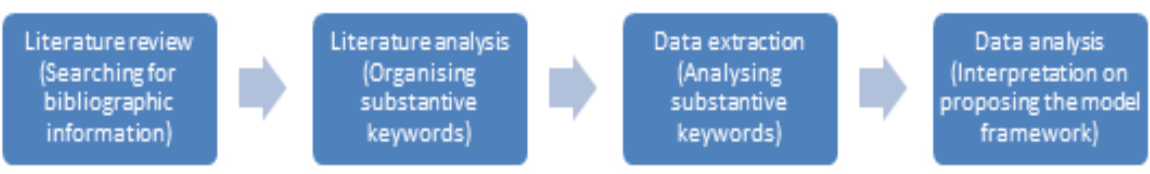

Fig. 2. Research Methodology

Figure 2 indicates the flow of how to design the research framework consisting of searching for relevant information using keywords. Then, analysis was also conducted by organizing substantive keywords. To extract data from the findings, further analysis of substantive keyword has been synthesized to interpret the finding to propose framework model.

\section{$4 \quad$ Analysis And Discussion}

\subsection{The Process of Big Data Analytic in Education}

As the new approach with the huge amounts of data created every second across the internet, big data analytic is defined as the capacity of new data correlations resulted from collecting, organizing and analyzing massive data [13]. It aims at discovering patterns with information contained in data analytics [22]. Extending variety, velocity and volume of data set from transferring and sharing the data, extracting big data which is added to become the value in supporting the learning process provides the access to data sources reliable to help users' engagement and interaction [14]. To enhance the users in getting more understanding towards the information, identifying large of data performed using certain software would help them to run their variety of any purpose in terms of business, education and many others. As a result of gaining 
better understanding, the further analysis with big data approach is basically an insightful attempt with the knowledge deriving from analyzing the data. By analyzing the large number of data, the applications with specialized software tools are eventually integrated for predictive analytics, forecasting, text and data mining and data optimization [23]. In this view, analytics with high performance in the process of massive data accumulated to see the relevant data which can go further to be the outstanding chance to decide any field is considered that collectively the process looks separately integrated, but it would be highly integrated performance analytics.

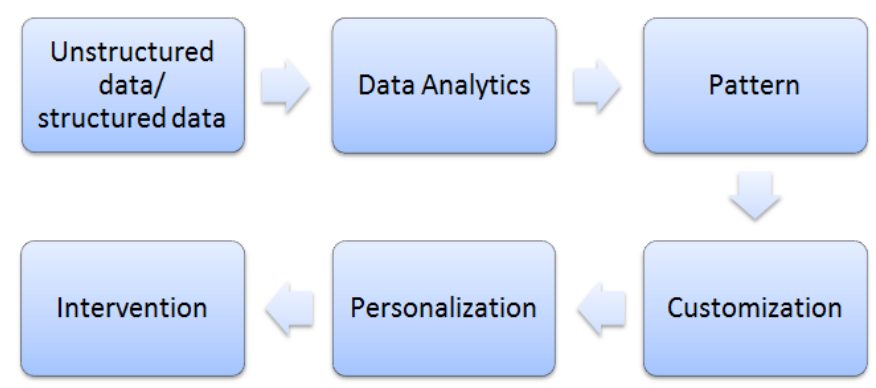

Fig. 3. The Process of Big Data Analytic in Education

As indicated on the Figure 3, the general concept shows big data in generating the value in education. Regarded as the data volume with the different formats including both structured and unstructured data across the entire organization and other institutions through many different ways, the combination of different types of data can be contrasted and analyzed to find patterns and other useful information [24]. The structured data sources come eventually from students' financial records, students' records, web click behaviors, e-library records, enterprise resource planning (ERP) records, etc [25]. On the other hand, unstructured data sources can come from social networks interactions, audio, and etc [26]. This analytics is to generate the process of extracting raw data in which the outcome of data analytic can be exerted to predict the pattern which enables the learner to deliver the information source. In delivering the service appropriately for student as a result of prediction and pattern, offering personalization of service, customization of modules, and intervention would lead to the quality control of performance. It aims at helping the run of the learning process. Moreover, the students' ability to choose and pick up any module or topic related to their interest is considered to be customization process. In particular, intervention is considered to give such attention when necessary for further performance due to the declining event. It can be seen when the student cannot perform well in specific course or topic, notification or alert can be sent to them.

\subsection{Understanding Modern Learning Environment in Big Data Era}

Understanding MLE as the term integrated between digital technology tools and learning skills together with convenient facilitations has a whole section designed to support learning styles which can exactly create the learning environment to be mod- 
ern. In this view, big data in the way that can be seen with a distinct look especially in the learning and teaching process has the characteristic on processing to facilitate in transferring the content of the learning sources which the learners look for [27]. It aims at improving the learning experience by enabling the learners to freely access such information resources.

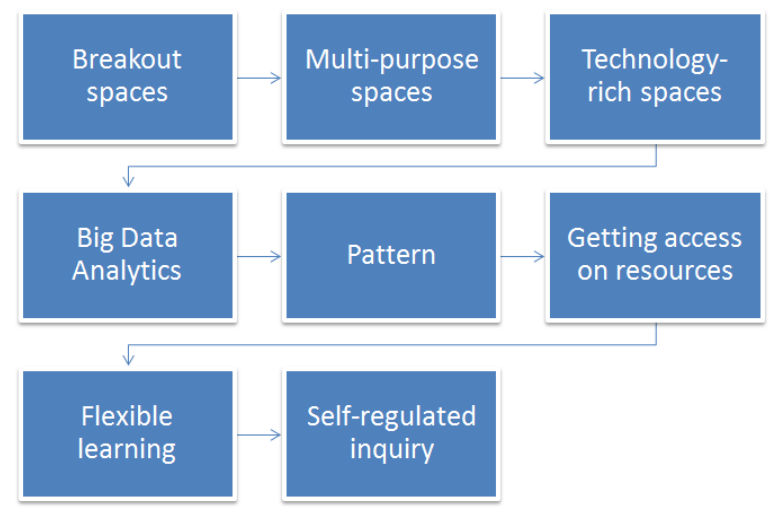

Fig. 4. Model of MLE in big data era

As illustrated in the figure 4, MLE combined among breakout spaces, multipurpose spaces and technology-rich spaces integrated with big data analytics process can help the learners to capture the knowledge into the 'pattern'. Then, this will make easily in 'getting access on the resources' adjusted to students' material subject. Moreover with the massive open online sources to effectively help them in finding out information, they may be working in the same online activities with this convenience. This refers to some particular additional facilitation in developing the learning activities to make the initiative for 'flexible learning'. As a result, creating students to discover and build largely on their own understanding of information which they enhance through conceptualizing principles and relationships which lead to strengthen their capabilities with 'self-regulated inquiry'. With this regard, big data integrated with the effective online learning can be enhanced in helping the learners to achieve the availability and easy access [28]. In particular, it can also facilitate the teaching competencies with core adaptive qualities to underlie teacher performances [19]. All these refer to enhance in gaining the technological interface design to give access in determining the usability in learning. Moreover, technology-based learning combined with class academic-based activities amongst an unlimited number of participants can be integrated frequently to enable individual behavior to possibly reflecting attempts provided from the instructor. To achieve this, it can be conducted from laptops into the class by using web-based searches, online surveys, interactive case-studies, published articles on the web and also online videos.

Towards optimizing the technological devices to utilize in getting access of information, big data with its data analytics enables to gain the distinct value featured in maximizing data potentials in online learning. In this view, customization and personalization of knowledge reached through maximizing the potential of data collection 
would lead to gain the personalized and customized services to every user in general and each student in particular [28]. As a result, this distinct feature in online learning systems could offer knowledge delivery with more precision to explore such data provided by the instructor in understanding the students' behavior in terms of which relevant sources may be enhanced to get access in supporting their learning. For instance, materials provided to students can be supplied through links which are relevant to the sources [29]. This is to enhance online learning process with developing the structure of subject material course to enable learners to obtain their records in supporting their needs like in school work or homework. At this point of view, the instructor here needs to recognize students' quality to adapt the reliable link delivered to them [30]. Attempts to posting various web of page frequently in understanding details of activities can be adjusted to provide such appropriate content obtained to their personal learning needs. In further, their activities recorded in data transmission can be transferred as a plat form to increasingly attract the attention with effective learning. The integration of data from volunteering the users' activities becomes an essential competence in that big data can generate the instructional design models [31]. To arrange the planning of big data integration, technology usage planned specifically in shaping the learners' way in the learning process needs to be prepared well to make sure that designed principle both inside and outside could be transferred to provide learners with experiences from which they can learn. In this regard, the technological competence needs to strengthen big data approach which is aimed at managing the way of learning with strategies innovation.

Enhancing Flexible Learning with Accessible Resources. Figure 5 shows model of enhancing flexible learning with accessible resources in big data era. MLE with the generic term to give the particular description in open and flexible space has potential value to supply the learning source by enabling the learners to access it easily [23]. Supported by big data analytics process, it can enhance the learning situated with flexibility to utilize technological devices in getting access on the subject material resources. Viewed typically as the learning surrounded by a range of wireless and wired technology, big data could offer access on the subject material of learning [32]. Moreover, this refers also to some particular additional facilitation mainly on the technology-rich spaces. As a result, the considerable chance to improve students' learning and outcomes can enhance the learning instrument in supporting learning styles on knowledge inquiry which can be facilitating the tools to create such bright on the flexible learning environment. In this regard, stimulating classrooms to enable student to accept the learning and additionally to get access to online resource can be employed to obtain the significance of generating big data analytics as the current trend in online learning to improving the practice of the technology's transformational impact [33]. With regard to improving the practical basis in maximizing online learning implementation, big data approach with its data analytics attempts to establish pattern which can be achieved through the communication commonly used among the users. In addition to adopting the Internet and computers, making an effective medium for educational institution is significant to handle many issues surrounding them such as difficulties on finding resources which is lack of any information available in printed version [34]. As the current learning trends, big data feature may be also ac- 
cessed in supporting teaching performance [35] with an innovative approach [19] to underlie learning and teaching process with offering an effort to make in getting such empowerment to the knowledge inquiry. As subsequent exploration, to achieve this, it has two core views which can be outstanding empowerment to enhance flexible learning with accessible resources, namely empowerment to get access to resources and empowerment to creating flexibility in learning.

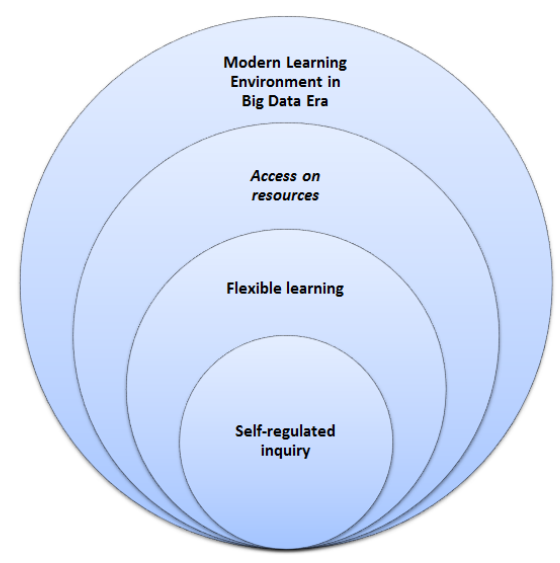

Fig. 5. Model of enhancing flexible learning with accessible resources in big data era

Empowering to get access on resources. MLE in big data era has to do with generating to give access on the resources. Since big data offers a high analytic data to analyze massive data, big data analytics generated with specialized software tools and applications can typically perform predictive analytics through any resources available in online [22]. This process will create data optimization coming from text mining and data mining. Moreover, it can be accessed by optimizing the mixture of wireless and wired technology in allowing getting any resources relevant to learning subject materials and activities, such as group work, reading and project space [36]. By offering access to fulfil the learning sources, reflection and presenting the flow of the learning in an open and flexible learning environment leads to a more robust [37]. As a result, the interventions contributed to collaboratively reflect on the data generation can improve the learning style which students may conduct. Such inquiries shared collaboratively on both self and peer observations leads to the reflections on big data approach which can be used both thoughtfully and effectively [38]. In particular, this benefit will look to provide integrated modules alongside structure of subject modules in providing opportunities for significant time in school-wide and passion projects. In this regard, big data has a significant essence to consider the value derived from the massive data of subject materials to drive the learning process. Subsequently, students and teachers need to work collaboratively in sharing information provided to ensure MLE can be a platform effectively to support the learner needs with focusing on selfregulated inquiry.

Empowering the learning with creating flexibility. With regard to creating flexibility in learning, the implementation of teaching and learning strategies and new 
approaches becomes important elements to underlie the learning outcomes. Flexible learning here is considered in accessing education implemented in the responsive way eventually with delivering online learning [27]. Empowerment supported by place, pace and mode of delivery system of learning in big data approach would lead to create flexibility in learning, since the learning resources can be provided by the software platform [31]. As a result, the strategy implementation with the use of transfer and accumulation credit becomes one of the important elements to facilitate the learning process to enhance the learning outcomes. Set out from accumulating and transferring the subject matter, the flexibility has the meaning to enable learning with accessing the responsive way combined with pace, place and delivery mode [39][54]. Creating flexibility to provide remote or online study here can be initiative on the teaching and learning process with a significant and strong role in utilizing big data analytics process. In addition to showing the lesson with the students' attitudes in their daily lives, it is necessary, therefore, for the teacher to take responsibility to make students more aware of space and flexibility in learning. Both self-regulated inquiry and work based inquiry can be combined to strengthen learners to achieve the quality in terms of process and outcomes [11] with adaptive technology skills referring to the careful engagement [40]. In particular, to achieve this purpose in the way that the lessons should be transformed amongst the learners needs to get improve in encouraging learners to obtain their learning effort with mechanical rules and [41][42]. Additionally, by generating actionable insights from their data customization, this is to make sure that such components including flexibility in learning can be enhanced to optimize the effectiveness of self-regulated inquiry with big data approach.

\section{$5 \quad$ Recommendation}

MLE in the context of supporting the learning enhancement could be managed through the potential value to the measurement on educational examination process for instance [43], where the essence of this initiative should be combined with employing the commitment during the process itself. In this view, attempts to strengthen the learning commitment in big data approach might be also engaged into the embodiment of personalised basis on spirituality empowerment [44]. As a result of continuing the innovative approach to support the learning the process using digital device, this valuable insight would need to maximise the theoretical basis through enhancing expertise diagnostic referring to the mathematical theory of evidence [45]. In particular, those three core emphasis which MLE has to do with big data approach could considerably assist the learning process through letting the resources to be accessed flexibly. Moreover, attempts to enhance the learning with flexibility in getting accessible on the resources provided in online would give the particular value in supplying the learning process more convenience. In this view, this initiative of flexible learning could deliver online learning determined by accessing the learning resources transmitted through the software platform learning with an innovative approach on online learning resources [46]. This entire point would give a contribution towards wide 
range of consolidations including civic responsibility and leadership [47], learning for corporate social responsibility [48], and learning enhancement [49] in the sense that is associated into the technology application strategy [50]. In supporting the counselling service for instance [51], and in the attempts to supply the learning source by enabling the learners to access it easily in engaging the moral integrity in learning interaction [52][53], the particular description to enhance the flexible learning with accessible resources should be determined to give access on the resources using big data analytics process. Providing an open and flexible space in the way which MLE could deliver the massive data with the generic distinction is supposed to provide the potential value in facilitating the responsive way in the learning process [54][55][56]. Situated with delivering flexibility in utilizing technological devices in the sense that big data offers a high analytic data to analyse massive data, getting access on the subject material resources implemented with empowerment supported by place, pace and mode of delivery system of learning in big data approach. This initiative would lead to create flexibility in learning in the attempts to generate big data analytics through specialized software tools and applications. Through typically performing the predictive analytics, empowering the implementation of teaching and learning strategies by enabling MLE in big data era could be a pivotal role in running the learning resources available in online. This would contribute to new approaches being the important elements to underlie the process and outcomes through getting access on resources to empowering the learning with creating flexibility in learning.

\section{Conclusion}

This paper does elaborate the design of MLE in big data era. By understanding the engagement of the current trend of big data era to see how its process can underlie the learning performance, we designed this model by examining literature reviews from peer-reviewed journals, books and conference papers by using keywords modern learning environment and big data. Understanding MLE model to enhance the learning performance with innovative way by incorporating big data framework in utilizing various sources of data, this paper provides the findings based on the theoretical foundations to see the chance in applying this model for the construction to the design of big data based learning environments to facilitate online learning towards information and knowledge in higher education setting. In addition to exploring the big data approach which students are engaged to access online resources using their mobile devices, laptop and other digital devices, understanding MLE as the term integrated between digital technology tools and learning skills together with convenient facilitations has a whole section designed to support learning styles which can exactly create the learning environment to be modern. Towards optimizing the technological devices to utilize in getting access of information, big data with its data analytics enables to gain the distinct value featured in maximizing data potentials in online learning. Supported by big data analytics process, it can enhance the learning situated with flexibility to utilize technological devices in getting access on the subject material resources. Big data analytics generated with specialized software tools and applica- 
tions can typically perform predictive analytics through any resources available in online. This process will create data optimization coming from text mining and data mining. Creating flexibility in learning here is considered in accessing education implemented in the responsive way eventually with delivering online learning. The implication of this paper is that big data approach would create pattern from voluntary sources in the virtual learning model to enable them in sustaining their behavior and learning. As a result, this paper is expected to contribute in the support with an initiative in the learning and teaching sectors as well as the professions to exchange ideas and examples of best practice which may be the reference amongst education researchers and professionals, policy makers and educators.

\section{$7 \quad$ References}

[1] Mulwa, C., Lawless, S., Sharp, M., Arnedillo-Sanchez, I., \& Wade, V. (2010, October). Adaptive educational hypermedia systems in technology enhanced learning: a literature review. In Proceedings of the 2010 ACM conference on Information technology education (pp. 73-84). ACM. https://doi.org/10.1145/1867651.1867672

[2] Leow, F. T., \& Neo, M. (2015). Redesigning the classroom environment to enhance students' collaborative learning activities. In Emerging Issues in Smart Learning (pp. 267274). Springer Berlin Heidelberg.

[3] Rennie, F., \& Morrison, T. (2013). E-learning and social networking handbook: Resources for higher education. New York and London: Routledge.

[4] de la Iglesia, D. G., Andersson, J., \& Milrad, M. (2010, November). Enhancing mobile learning activities by the use of mobile virtual devices--some design and implementation issues. In Intelligent Networking and Collaborative Systems (INCOS), 2010 2nd International Conference on (pp. 137-144). IEEE.

[5] Page, T., \& Thorsteinsson, G. (2008). Innovative technology education using a virtual reality learning environment. Pedagogika, (90), 26-35.

[6] Jonassen, D., \& Land, S. (Eds.). (2012). Theoretical foundations of learning environments. New York and London: Routledge.

[7] Osborne, M. (2013). Modern learning environments. The CORE education blog.

[8] Leow, F. T., \& Neo, M. (2015). Redesigning the classroom environment to enhance students' collaborative learning activities. In Emerging Issues in Smart Learning (pp. 267274). Springer Berlin Heidelberg.

[9] Bingimlas, K. A. (2009). Barriers to the successful integration of ICT in teaching and learning environments: A review of the literature. Eurasia Journal of Mathematics, Science \& Technology Education, 5(3), 235-245. https://doi.org/10.12973/ejmste/75275

[10] Bereiter, C. (2002). Design research on learning environments. Design research for sustained innovation. 認知科学, 9(3), 321-327.

[11] McLoughlin, C., \& Lee, M. J. (2010). Personalised and self-regulated learning in the Web 2.0 era: International exemplars of innovative pedagogy using social software. Australasian Journal of Educational Technology, 26(1), 28-43. https://doi.org/ $10.14742 /$ ajet. 1100

[12] Vänttinen, M., \& Pyhältö, K. (2009). Strategy process as an innovative learning environment. Management Decision, 47(5), 778-791. https://doi.org/10.1108/00251740910960114

[13] Kitchin, R. (2014). Big Data, new epistemologies and paradigm shifts. Big Data \& Society, April-June: 1-12. 
[14] Villars, R. L., Olofson, C. W., \& Eastwood, M. (2011). Big data: What it is and why you should care. White Paper, IDC.

[15] Lyon, D. (2014). Surveillance, snowden, and big data: capacities, consequences, critique. Big Data \& Society, July-December: 1-13 https://doi.org/10.1177/2053951714541861

[16] Mayer-Schönberger, V., \& Cukier, K. (2013). Big data: A revolution that will transform how we live, work, and think. Houghton Mifflin Harcourt.

[17] Lohr, S. (2012). The age of big data. New York Times, 11.

[18] Mosco, V. (2015). To the cloud: Big data in a turbulent world. New York and London: Routledge.

[19] Huda, M., Anshari, M., Almunawar, M. N., Shahrill, M., Tan, A., Jaidin, J. H., \& Masri, M. (2016). Innovative Teaching in Higher Education: The Big Data Approach. The Turkish Online Journal of Educational Technology, 15(Special issue), 1210-1216.

[20] Anshari, M., Alas, Y., Sabtu, N. I. P. H., \& Hamid, M. H. S. A. (2016). Online Learning: trends, issues and challenges in the Big data era. Journal of e-Learning and Knowledge Society, 12(1).

[21] Anshari, M., Alas, Y., \& Guan, L. S. (2016). Developing online learning resources: Big data, social networks, and cloud computing to support pervasive knowledge. Education and Information Technologies, 21(6), 1663-1677. https://doi.org/10.1007/s10639-0159407-3

[22] Zikopoulos, P., \& Eaton, C. (2011). Understanding big data: Analytics for enterprise class hadoop and streaming data. McGraw-Hill Osborne Media.

[23] Mahrt, M., \& Scharkow, M. (2013). The value of big data in digital media research. Journal of Broadcasting \& Electronic Media, 57(1), 20-33. https://doi.org/10.1080/ 08838151.2012 .761700

[24] LaValle, S., Lesser, E., Shockley, R., Hopkins, M. S., \& Kruschwitz, N. (2011). Big data, analytics and the path from insights to value. MIT sloan management review, 52(2), 21.

[25] Srinivasa, S., \& Bhatnagar, V. (2012). Big data analytics. In Proceedings of the First International Conference on Big Data Analytics BDA (pp. 24-26). https://doi.org/10.1007/ 978-3-642-35542-4

[26] Cuzzocrea, A., Song, I. Y., \& Davis, K. C. (2011, October). Analytics over large-scale multidimensional data: the big data revolution!. In Proceedings of the ACM 14th international workshop on Data Warehousing and OLAP(pp. 101-104). ACM. https://doi.org/10.1145/2064676.2064695

[27] Begoli, E., \& Horey, J. (2012, August). Design principles for effective knowledge discovery from big data. In Software Architecture (WICSA) and European Conference on Software Architecture (ECSA), 2012 joint working IEEE/IFIP conference on (pp. 215-218). IEEE.

[28] Chen, M., Mao, S., \& Liu, Y. (2014). Big data: a survey. Mobile Networks and Applications, 19(2), 171-209. https://doi.org/10.1007/s11036-013-0489-0

[29] Anshari, M., Almunawar, M. N., Shahrill, M., Wicaksono, D. K., \& Huda, M. (2017). Smartphones usage in the classrooms: Learning aid or interference?. Education and Information Technologies, 1-17. https://doi.org/10.1007/s10639-017-9572-7

[30] Othman, R., Shahrill, M., Mundia, L., Tan, A., \& Huda, M. (2016). Investigating the Relationship Between the Student's Ability and Learning Preferences: Evidence from Year 7 Mathematics Students. The New Educational Review, 44(2), 125-138.

[31] Najafabadi, M. M., Villanustre, F., Khoshgoftaar, T. M., Seliya, N., Wald, R., \& Muharemagic, E. (2015). Deep learning applications and challenges in big data analytics. Journal of Big Data, 2(1), https://doi.org/10.1186/s40537-014-0007-7 
[32] Katal, A., Wazid, M., \& Goudar, R. H. (2013, August). Big data: issues, challenges, tools and good practices. In Contemporary Computing (IC3), 2013 Sixth International Conference on (pp. 404-409). IEEE. https://doi.org/10.1109/IC3.2013.6612229

[33] Huda, M., Shahrill, M., Maseleno, A., Jasmi, K. A., Mustari, I., \& and Basiron, B. (2017a). Exploring Adaptive Teaching Competencies in Big Data Era. International Journal of Emerging Technologies in Learning 12(3), 68-83. https://doi.org/10.3991/ijet.v12i03.6434

[34] Murphy, D., Walker, R., \& Webb, G. (2013). Online learning and teaching with technology: case studies, experience and practice. New York and London: Routledge.

[35] Duhaney, D. C. (2001). Teacher education: Preparing teachers to integrate technology. International Journal of Instructional Media, 28(1), 23.

[36] Hoi, S. C., Wang, J., Zhao, P., \& Jin, R. (2012, August). Online feature selection for mining big data. In Proceedings of the 1st international workshop on big data, streams and heterogeneous source mining: Algorithms, systems, programming models and applications (pp. 93-100). ACM.

[37] Manca, S., Caviglione, L., \& Raffaghelli, J. E. (2016). Big data for social media learning analytics: potentials and challenges. Journal of e-Learning and Knowledge Society, 12(2).

[38] Fisher, D., DeLine, R., Czerwinski, M., \& Drucker, S. (2012). Interactions with big data analytics. interactions, 19(3), 50-59. https://doi.org/10.1145/2168931.2168943

[39] Mainemelis, C., Boyatzis, R. E., \& Kolb, D. A. (2002). Learning styles and adaptive flexibility testing experiential learning theory. Management learning, 33(1), 5-33. https://doi.org/10.1177/1350507602331001

[40] Huda, M., Jasmi, K. A., Hehsan, A., Shahrill, M., Mustari, M. I., Basiron, B., \& Gassama, S. K. (2017b). Empowering Children with Adaptive Technology Skills: Careful Engagement in the Digital Information Age. International Electronic Journal of Elementary Education, 9(3), 693-708.

[41] Huda, M., Jasmi, K. A., Basiran, B., Mustari, M. I. B., \& Sabani, A. N. (2017c). Traditional Wisdom on Sustainable Learning: An Insightful View From Al-Zarnuji's Ta 'lim alMuta 'allim. SAGE Open, 7(1), 1-8. https://doi.org/10.1177/2158244017697160

[42] Wang, C. L., \& Ahmed, P. K. (2003). Organisational learning: a critical review. The learning organization, 10(1), 8-17. https://doi.org/10.1108/09696470310457469

[43] Maseleno, A., Huda, M., Siregar, M., Ahmad, R., Hehsan, A., Haron, Z., Ripin, M.N., Ihwani, S.S., and Jasmi, K.A. (2017). Combining the Previous Measure of Evidence to Educational Entrance Examination. Journal of Artificial Intelligence 10(3), 85-90. https://doi.org/10.3923/jai.2017.85.90

[44] Huda., M. \& Sabani, N. (2018). Empowering Muslim Children's Spirituality in Malay Archipelago: Integration between National Philosophical Foundations and Tawakkul (Trust in God). International Journal of Children's Spirituality 1-14. https://doi.org/10.1080/ 1364436X.2018.1431613

[45] Maseleno, A., Pardimin, Huda, M., Ramlan, Hehsan, A., Yusof, Y.M., Haron, Z., Ripin, M.N., Nor, N.H.M., and Junaidi, J. (2018). Mathematical Theory of Evidence to Subject Expertise Diagnostic. ICIC Express Letters, 12 (4).

[46] Huda, M., Maseleno, A., Muhamad, N.H.N., Jasmi, K.A., Ahmad, A., Mustari, M.I., Basiron, B. (2018a). Big Data Emerging Technology: Insights into Innovative Environment for Online Learning Resources. International Journal of Emerging Technologies in Learning 13(1), 23-36. https://doi.org/10.3991/ijet.v13i01.6990

[47] Huda, M., Teh, K.S.M., Nor, N.H.M., and Nor, M.B.M. (2018b). Transmitting Leadership Based Civic Responsibility: Insights from Service Learning. International Journal of Ethics and Systems, 34(1), 20-31. https://doi.org/10.1108/IJOES-05-2017-0079 
[48] Huda, M. (2018a). Empowering Application Strategy in the Technology Adoption: Insights from Professional and Ethical Engagement. Journal of Science and Technology Policy Management. (accepted for publication). https://doi.org/10.1108/JSTPM-09-2017-0044

[49] Huda, M. (2018b). Empowering Corporate Social Responsibility (CSR): Insights from Service Learning. Social Responsibility Journal. (accepted for publication).

[50] Huda, M. (2018c). Building Harmony in Diverse Society: Insights from Practical Wisdom. International Journal of Ethics and Systems. (accepted for publication).

[51] Huda, M., Jasmi, K. A., Mustari, M. I., Basiron, B., Mohamed, A. K., Embong, W., ... \& Safar, J. (2017d). Innovative E-Therapy Service in Higher Education: Mobile Application Design. International Journal of Interactive Mobile Technologies, 11(4), 83-94. https://doi.org/10.3991/ijim.v11i4.6734

[52] Huda, M., Siregar, M., Ramlan, Rahman, S.K.A., Mat Teh, K.S., Said, H., Jamsari, E.A., Yacub, J., Dacholfany, M.I., \& Ninsiana, W. (2017e). From Live Interaction to Virtual Interaction: An Exposure on the Moral Engagement in the Digital Era. Journal of Theoretical and Applied Information Technology, 95(19), 4964-4972.

[53] Huda, M., Maseleno, A., Jasmi, K. A., Mustari, I., \& Basiron, B. (2017f). Strengthening Interaction from Direct to Virtual Basis: Insights from Ethical and Professional Empowerment. International Journal of Applied Engineering Research, 12(17), 6901-6909.

[54] Huda, M., Haron, Z., Ripin, M. N., Hehsan, A., \& Yaacob, A. B. C. (2017g). Exploring Innovative Learning Environment (ILE): Big Data Era. International Journal of Applied Engineering Research, 12(17), 6678-6685.

[55] Huda, M., Yusuf, J. B., Jasmi, K. A., \& Nasir, G. A. (2016b). Understanding Comprehensive Learning Requirements in the Light of al-Zarnūjī’s Ta'līm al-Muta'allim. Sage Open, 6(4), 1-14. https://doi.org/10.1177/2158244016670197

[56] Huda, M., Sabani, N., Shahrill, M., Jasmi, K. A., Basiron, B., \& Mustari, M. I. (2017h). Empowering Learning Culture as Student Identity Construction in Higher Education. In A. Shahriar, \& G. Syed (Eds.), Student Culture and Identity in Higher Education (pp. 160179). Hershey, PA: IGI Global. https://doi.org/10.4018/978-1-5225-2551-6.ch010

\section{Authors}

Miftachul Huda is with Universiti Teknologi Malaysia, Malaysia.

Andino Maseleno is with STMIK Pringsewu, Lampung, Indonesia.

Kamarul Shukri Mat Teh is with Universiti Sultan Zainal Abidin, Malaysia.

Abdul Ghafar Don is with Universiti Kebangsaan Malaysia, Malaysia.

Bushrah Basiron is with Universiti Teknologi Malaysia, Malaysia.

Kamarul Azmi Jasmi is with Universiti Teknologi Malaysia, Malaysia.

Mohd Ismail Mustari is with Universiti Teknologi Malaysia, Malaysia.

Badlihisham Mohd Nasir is with Universiti Teknologi Malaysia, Malaysia.

Roslee Ahmad is with Universiti Islam Sains Malaysia, Malaysia.

Article submitted 29 November 2017. Resubmitted 24 February 2018. Final acceptance 25 March 2018. Final version published as submitted by the authors. 